\title{
Awareness, Knowledge and Practices of Breast Cancer Prevention among Women with Family History of Breast Cancer in Ede, Osun State, Nigeria
}

\author{
Ademola Lukman Adelekan ${ }^{1}$, Elizabeth Ronami Edoni ${ }^{2}$ \\ ${ }^{I}$ (Health Promotion and Education Department, College of Medicine/University of Ibadan, Nigeria) \\ ${ }_{2}^{2}$ (Department of Community Health, College of Health Sciences/Niger Delta University, Wilberforce Island, \\ Nigeria)
}

\begin{abstract}
Women with Family History (FH) of Breast Cancer (BRCA) in first-degree relative have a relative risk $>4$ due to inherited genetic mutation genes. This study therefore assessed knowledge and practices of $B R C A$ prevention among women with FH of BRCA in the study area.

This is a cross-sectional study. Snowball sampling technique was used to select 189 women with FH of BRCA. A semi-structured questionnaire was used to obtained data and Descriptive statistics and t-test were used for the analysis.

Respondents mean age was $43.4 \pm 9.2$ years. Some (42.9\%) were not aware of their susceptibility to BRCA. Some (42.9\%) of respondents have family members who had died of BRCA and $13.2 \%$ have family members who currently have BRCA. Many (61.4\%) believed that BRCA is not curable even when detected early and $65.1 \%$ did not know that painless lump in the breast is one of the signs of BRCA. Preventive practices among respondents included regular taking of herbs (67.5\%) and breastfeeding for longer than 1 year $(14.5 \%)$. Majority (96.3\%) and 38.6\% have never performed mammogram and breast self examination respectively.

Incorrect preventive practices existed among respondents. Information, education and communication programme on breast cancer prevention should be intensified for these women.
\end{abstract}

Keywords: Awareness, Breast Cancer, Family History, Knowledge, Practices

\section{Introduction}

There are diverse risk factors that may affect each woman's susceptibility to Breast Cancer (BRCA) [1]. Family History $(\mathrm{FH})$ of BRCA has been scientifically documented as one of the risk factors associated with it. BRCA is the commonest cancer among women in the world and in Nigeria [2]. The relative frequencies of BRCA among other female cancers, from Cancer Registries in Nigeria were 35.3\% in Ibadan, $28.2 \%$ in IfeIjesha, $44.5 \%$ in Enugu, 17\% in Eruwa, 37.5\% in Lagos, 20.5\% in Zaria and 29.8\% in Calabar [3]. In all the centers, except Calabar and Eruwa, breast cancer rated first among other cancers. Further reports showed that majority of cases occurred in pre menopausal women, and the mean age of occurrence ranged between 43-50 years across the regions. The youngest age recorded was 16 years, from Lagos [3]. Adebamowo and Ajayi [2] also reported that peak age of incidence in Nigeria is 42.6 years, and that $12 \%$ of cases occurred before 30 years while postmenopausal women accounted for $20 \%$ of cases. In a recent oncological review of cases in Jos, Nigeria, over an 8-year period, BRCA was reported to account for $56.6 \%$ of all cancer diagnosis between 1995 2002 [4]. Among Nigerian women, the peak age of BRCA presentation is about 10-15years earlier than what is observed in Caucasian women, where it occurs between the ages of 35-45 years. Seventy percent of Nigerian women present with advanced staged disease while the five-year survival rate is less than $10 \%$ compared with over 70\% in Western Europe and North America [5]. Odusanya found BRCA to be the most common surgical condition women worry about in a list of eleven comparable conditions [6]. According to Odusanya, BRCA is not well understood by women and there is a need for information and enlightenment if they are to present early in hospital. Among Nigerian women, some of the factors preventing early hospital presentation and thus increasing mortalities are thought to include inadequacy of systems protecting and promoting women's health and cultural taboos regarding the female body. Lack of knowledge about BRCA has also been identified as an important factor preventing women from participating in BRCA screening. Few studies have examined the knowledge, attitude and practice of women towards BRCA in Nigeria $[6,7,8$,$] . These studies are often of small$ sample size and targeted women in special professions. We are unaware of any study that has examined these issues among women with FH of BRCA who constitute the majority of at risk women both for the disease and late presentation. This study recruiting 189 women with FH of BRCA in both urban and rural communities in Nigeria was designed to evaluate the knowledge and practice of these women towards BRCA. 


\subsection{Study Area}

\section{Methods}

Ede is located at $10^{\circ} 27^{\prime}$ North and $13^{\circ} 27^{\prime}$ East. Ede is in the Osun State, which is in the south western part of Nigeria. Ede is situated on the banks of Oshun River near Ibadan. However the city is practically built on railroad. The people are Yorubas. Among the higher institutions located in Ede, are the Federal Polytechnic and the Redeemed Christian Church of God Bible College. Several mosques and churches dot the land scape. Historically, it was an important town in Yorubaland. Egungun festival is still widely celebrated, like many other traditional festivals. However, more and more people are celebrating Christmas, New Year's Day and Ileya (Id-el Kabir) festival. In fact, throughout Nigeria, Id-el Kabir is celebrated most in Ede.

\subsection{Study design}

The study was conducted as a descriptive cross-sectional survey among women with Family History of Breast Cancer in Ede, Osun State, Nigeria. The study sought to determine the respondents' level of awareness of their susceptibility, knowledge of Breast Cancer and preventive practices. The data collection was carried out between June and August, 2010.

\subsection{Study Procedures/Instrument}

A total of 189 women with family history of breast cancer in first-degree relative(s) were used for the study. A self-administered questionnaire was used to obtain relevant socio-demographic characteristics, awareness, knowledge, and practice towards BRCA from respondents'. The questionnaire was developed by the authors based on information in the literature on risk factors, common signs and symptoms of BRCA and common methods of early detection. Snowball sampling procedure was adopted to select respondents' for the study.

\subsection{Data Collection Procedure}

A pre-tested interviewer administered semi structured questionnaire was used to interview 189 women with family history of breast cancer in first degree relative in Ede, Nigeria. The questionnaire was pre-tested in Iwo, a community similar to Ede in socio-demographic characteristics and necessary amendments made subsequently.

\subsection{Data Analysis}

A coding guide was developed by the researchers and was used in coding the questionnaires. Data entry and analysis were done by expert statistician using SPSS software. Descriptive statistics and Chi-Square were used. Frequencies were generated and cross tabulation of some variable.

\subsection{Demographic Characteristics}

\section{Results}

The age of the respondents' ranged from 25 to 62 years with the mean age of $43.4 \pm 9.2$ years. Majority $169(89.4 \%)$ were married and $10(5.3 \%)$ were widow. All (100\%) of the respondents' were Yoruba. Higher proportion $77(40.7 \%)$ of the respondents' have no education, $30(15.9 \%)$ have either Ordinary National Diploma (OND) or National Certificate of Education (NCE) and 18 (9.5\%) have either Higher National Diploma (HND) or First Degree (B.Sc). Table 1

Table 1: Socio-demographic characteristics of the Participants

\begin{tabular}{|l|l|l|}
\hline Variable & $\begin{array}{l}\mathbf{N}=189 \\
\text { No }\end{array}$ & $\mathbf{\%}$ \\
\hline Age (years) & & \\
25-34 & 29 & 15.3 \\
$35-44$ & 65 & 34.4 \\
$45-54$ & 66 & 34.9 \\
$55-64$ & 29 & 15.3 \\
\hline Marital status: & & \\
Single & 5 & 2.6 \\
Married & 169 & 89.4 \\
Seperated & 5 & 2.6 \\
Widower & 10 & 5.3 \\
\hline Religion practice: & & \\
Christianity & 55 & 29.1 \\
Islam & 134 & 70.9 \\
\hline
\end{tabular}




\begin{tabular}{|l|l|l|}
\hline Educational Status: & & \\
No Education & 77 & 40.7 \\
Primary School & 45 & 23.8 \\
Secondary Education & 19 & 10.1 \\
OND/NCE & 30 & 15.9 \\
HND/BSC & 18 & 9.5 \\
\hline Ethnic group: & & \\
Yoruba & 189 & 100.0 \\
\hline
\end{tabular}

\subsection{Awareness of Breast Cancer}

Many $81(42.9 \%)$ of the respondents were not aware of their susceptibility to BRCA and $25(13.2 \%)$ currently have family member(s) who currently have BRCA. These family members were Mother $12(6.3 \%)$, Sister $12(6.3 \%)$ and Grandmother $1(0.5 \%)$. Some $38(20.1 \%)$ have family member(s) who had died of BRCA and these members were Mother 18 (9.5\%), Sister $3(1.6 \%)$ and Grandmother 17 (9.0\%). Table 2

Table 2: Awareness of BRCA

\begin{tabular}{|l|l|l|}
\hline Variable & $\begin{array}{l}\text { N=189 } \\
\text { No }\end{array}$ & \% \\
\hline Awareness of susceptibility to & & \\
BRCA & 108 & 57.1 \\
Yes & 81 & 42.9 \\
No & & \\
\hline Aware of family member who \\
currently have BRCA & 25 & 13.2 \\
Yes & 164 & 86.8 \\
No & & \\
\hline Members who currently have & & \\
BRCA & 12 & 6.3 \\
Mother & 12 & 6.3 \\
Sister & 1 & 0.5 \\
Grandmother & & \\
\hline Awareness of family member who & & \\
had died of BRCA & 38 & 20.1 \\
Yes & 151 & 79.9 \\
No & & \\
\hline Members who had died of BRCA & 18 & 9.5 \\
Mother & 3 & 1.6 \\
Sister & 17 & 9.0 \\
Grandmother & & \\
\hline
\end{tabular}

\subsection{Participants' Knowledge of Breast Cancer}

The knowledge of the respondents on BRCA was assessed by posing seventeen true or false statements. As shown in Table 3, respondents had varying degree of knowledge on the risk factors, signs and symptoms and prevention of BRCA. A 17-point knowledge scale was used to measure the respondents' knowledge. A positive knowledge attracted a score of 1 point while the score for a negative knowledge was zero. A total score of $<9$ and $\geq 9$ points were considered poor and good knowledge respectively. The overall mean knowledge score of the respondents' was $8.31 \pm 2.7$. One hundred and seven $(56.6 \%)$ of the respondents had a poor knowledge while the remaining $43.4 \%$ had a good knowledge. Majority 185 (97.9\%) of the respondents did not know that BRCA is not only the disease of women and 25.9\% believed that BRCA is mostly caused by spiritual powers. Eighty one (42.9\%) did not know that FH of BRCA is one of the risk factors of BRCA. Table 3 
Awareness, Knowledge and Practices of Breast Cancer Prevention among Women with Family

Table 3 Knowledge on Breast Cancer

\begin{tabular}{|c|c|c|c|c|}
\hline & Knowledge of Breast Cancer & Yes & No & \\
\hline 1. & Breast cancer is strictly a disease of women & $185(97.9 \%)$ & $4(2.1 \%) *$ & \\
\hline 2 & $\begin{array}{l}\text { Breast cancer is mostly caused by spiritual } \\
\text { powers }\end{array}$ & $49(25.9 \%)$ & $140(74.1 \%)^{*}$ & \\
\hline 3 & $\begin{array}{l}\text { Exposure to multiple chest x-rays increases the } \\
\text { chances of breast cancer }\end{array}$ & $119(63.0 \%)^{*}$ & $70(37.0 \%)$ & \\
\hline 4 & $\begin{array}{l}\text { Exposure to ionizing radiation increases the } \\
\text { chances of breast cancer }\end{array}$ & $117(61.9 \%)^{*}$ & $72(38.1 \%)$ & \\
\hline 5 & $\begin{array}{l}\text { High alcohol consumption increases the } \\
\text { chances of having breast cancer }\end{array}$ & $47(24.9 \%)^{*}$ & $142(75.1 \%)$ & \\
\hline 6 & Breast cancer is curable if detected early & $73(38.6 \%)^{*}$ & $116(61.4 \%)$ & \\
\hline & & Yes & No & Don't Know \\
\hline 7 & \begin{tabular}{ll}
\multicolumn{2}{l}{ Risk factors for breast cancer } \\
a. & Family history of breast cancer \\
b. & Obesity \\
c. & Regular exercise \\
d. & Exclusive breast feeding
\end{tabular} & $\begin{array}{l}108(57.1 \%)^{*} \\
65(34.4 \%)^{*} \\
0(0.0 \%) \\
38(20.1 \%)\end{array}$ & $\begin{array}{l}81(42.9 \%) \\
113(59.8 \%) \\
189(100 \%)^{*} \\
145(76.7 \%)^{*}\end{array}$ & $\begin{array}{l}0(0.0 \%) \\
11(5.8 \%) \\
0(0.0 \%) \\
6(3.2 \%)\end{array}$ \\
\hline 8 & $\begin{array}{l}\text { Signs and symptoms of breast cancer } \\
\text { a. } \quad \text { Painless lump in the breast } \\
\text { b. } \quad \text { Ulcer of the breast } \\
\text { c. } \quad \text { Bloody discharge from the nipple }\end{array}$ & $\begin{array}{l}66(34.9 \%)^{*} \\
189(100.0 \%)^{*} \\
189(100.0 \%)^{*}\end{array}$ & $\begin{array}{l}123(65.1 \%) \\
0(0.0 \%) \\
0(0.0 \%)\end{array}$ & $\begin{array}{l}0(0.0 \%) \\
0(0.0 \%) \\
0(0.0 \%)\end{array}$ \\
\hline 9 & $\begin{array}{ll}\text { Ways of diagnosing breast cancer } \\
\text { a. } & \text { Mammography screening } \\
\text { b. } & \text { Self breast examination } \\
\text { c. } & \text { Fine needle aspiration } \\
\text { d. } & \text { Chest X-rays }\end{array}$ & $\begin{array}{l}26(13.8 \%)^{*} \\
149(78.8 \%)^{*} \\
4(2.1 \%)^{*} \\
10(5.3 \%)\end{array}$ & $\begin{array}{l}8(4.2 \%) \\
4(2.1 \%) \\
11(5.8 \%) \\
23(12.2 \%)^{*}\end{array}$ & $\begin{array}{l}155(82.0 \%) \\
36(19.0 \%) \\
174(92.1 \%) \\
156(82.5 \%)\end{array}$ \\
\hline
\end{tabular}

* correct responses

\subsection{Participants' practice of early detection measures of BRCA}

Many 73 (38.6\%) and 96.3\% of respondents' have never performed Breast Self Examination (BSE) and mammography screening respectively. Reasons given for the poor early detection screening practices were lack of knowledge on how BSE is done 75 (39.7\%), unawareness of mammography screening service availability $51(27.0 \%)$ and fear of discovering abnormalities (82.7\%). Table 4

Table 4: Practice of early detection of BRCA

\begin{tabular}{|l|l|l|l|}
\hline & & \multicolumn{1}{|c|}{ Yes } & No \\
\hline 1. & Ever performed BSE & $116(61.4 \%)$ & $73(38.6 \%)$ \\
\hline 2. & Ever performed mammogram & $7(3.7 \%)$ & $182(96.3 \%)$ \\
\hline
\end{tabular}

\subsection{Preventive practices of $B R C A$ by respondents,}

Preventive practices mentioned by respondents' were regular taking of herbs $(29.6 \%)$, breastfeeding longer than 1 year $(6.3 \%)$, and regular exercise $(30.2 \%)$. Table 5

Table 5: Practices of BRCA prevention

\begin{tabular}{|l|l|l|}
\hline & \multicolumn{1}{|c|}{ BRCA prevention practices } & \multicolumn{1}{|c|}{ Freq./\% } \\
\hline 1. & Breastfeeding longer than 1 year & $12(6.3 \%)$ \\
\hline 2. & Regular taking of herbs & $56(29.6 \%)$ \\
\hline 3. & Weight loss & $4(2.1 \%)$ \\
\hline 4. & Regular medical check up & $37(19.6 \%)$ \\
\hline 5. & Regular exercise & $57(30.2 \%)$ \\
\hline 6. & Improved hygiene & $11(5.8 \%)$ \\
\hline
\end{tabular}

\subsection{Determinants of BRCA knowledge}

The mean knowledge score of the respondents was low $(8.3 \pm 2.7)$. Only $82(43.4 \%)$ have a knowledge score of $\geq 9$. A large proportion $46(56.9 \%)$ of respondents in age group 35-44 year have higher level of 
knowledge compared with other age groups $36(43.9 \%)\left(X^{2}=70.9, \mathrm{df}=3, \mathrm{p}=0.00\right)$. We also assessed the association of knowledge score with level of education. There were $82(43.4 \%)$ study participants who have good knowledge score. A smaller proportion $39(47.6 \%)$ of respondents with secondary school education and below have good knowledge score compared with 43 (52.4\%) of those with education level above secondary school. Higher level of education was significantly associated with knowledge score $\left(X^{2}=88.7, \mathrm{df}=4, \mathrm{p}=0.00\right)$.

There is also a significant association between respondents' knowledge score and awareness of their susceptibility to BRCA. A total of $108(57.1 \%)$ respondents were aware of their susceptibility and $82(43.4 \%)$ have a good knowledge score. A larger proportion 67 (81.7\%) of respondents who are aware of their susceptibility have a good knowledge score compared with $15(18.3 \%)$ who were not aware of their susceptibility $\left(\mathrm{X}^{2}=35.7, \mathrm{df}=1, \mathrm{p}=0.00\right)$.

\subsection{Determinant of mammography screening practice}

The association between the use of mammography screening and level of education was assessed. Only 7 (3.7\%) respondents have ever performed mammogram and all of them are respondents with HND/First Degree. This shows that educational level is significant with the use of mammography screening as an early detection of BRCA $\left(\mathrm{X}^{2}=69.1, \mathrm{df}=4, \mathrm{p}=0.00\right)$. There was no significant association between respondents' awareness of their susceptibility to BRCA and use of mammography service.

\subsection{Determinant of BSE practices}

Respondents' practice of BSE was also assessed with level of education. There were 73 (38.6\%) of respondents who have never performed BSE. A larger proportion $61(83.6 \%)$ of respondents with secondary school education and below have never performed BSE compared with $12(16.4 \%)$ of those with education level above secondary school. Higher level of education was significantly associated with practiced of BSE $\left(X^{2}=43.4\right.$, $\mathrm{df}=4, \mathrm{p}=0.00)$.

A significant association was also found between respondents' awareness of their susceptibility and practice of BSE. A total of $108(57.1 \%)$ respondents were aware of their susceptibility and $116(61.4 \%)$ have ever performed BSE. A larger proportion $86(74.1 \%)$ of respondents who are aware of their susceptibility have ever performed BSE compared with $30(25.9 \%)$ who were not aware of their susceptibility $\left(X^{2}=35.4, \mathrm{df}=1, \mathrm{p}\right.$ $=0.00)$.

\section{Discussion}

This study revealed that majority of the population had no formal education. The educational structure is the same with the study conducted in Ibadan, Nigeria in which $56.5 \%$ of the study population had no formal education [16] and another study [9] in a sub urban population also reported that $33.2 \%$ of the population had no formal education. Majority of the respondents was in the 35-54 year age group. This age group of women are more vulnerable to breast cancer compared with other women in other age group. This age structure is different from that of a study conducted in Ibadan where more than half of the study population was in the 20-40 year age group where many of the older women declined to participate in the study [16].

The results of this study suggest that women with family history of breast cancer in first degree relative(s) have a poor knowledge of breast cancer. This may partly explain the late presentation of breast cancer among women. This finding is similar to the study [15]. The poor level of knowledge found in this study is in keeping with reports of other investigators $[6,7,8]$. In a survey of breast cancer knowledge, Uche [8] noted that only $32 \%$ of the respondents knew that a breast lump was a warning sign for breast cancer, $58.5 \%$ were unaware of the most warning signs and only $9.8 \%$ knew of methods of detecting breast cancer. The findings of another study in Iran showed that only $44.0 \%$ of women said that painless lump is a common symptom of breast cancer [17]. Our study also showed that majority of women with family history of breast cancer were not aware of a painless breast lump as a common presentation of breast cancer and only $13.8 \%$ were aware of mammography as a screening tool for breast cancer. This is consistent with other studies from developing countries and women from minority ethnic groups [13,14], whereas a study from U.K indicated that $70.0 \%$ of women were well aware of painless lump and able to identify these symptoms in their breast self-examination [12]. In Nigeria, even professional health workers such as nurses who are supposed to be leaders in breast awareness were reported to have similar low knowledge scores [7]. Odusanya and Tayo [7] found that only $27 \%$ of nurses in a tertiary health institution in Lagos, Nigeria could identify up to 3-4 risk factors for breast cancer. In addition, $51 \%$ of these nurses wrongly identified the use of fingertips in performing BSE. All the respondents knew that bloody discharge from nipple is a warning sign of breast cancer. This finding is not in accord with a study in Iran [17] which showed that only $6.0 \%$ women knew bloody discharged from nipple as a warning sign of breast cancer.

The use of screening methods was very low among our study respondents. Majority and some of the respondents did not know that mammography and breast self-examination respectively as ways of diagnosing breast cancer. This agrees with a previous study [15] which also showed that the use of screening methods was 
very low among the study subjects where only $34.9 \%$ practiced BSE in the past year and none ever had a mammogram. In a study by Jacobs et al, [10] on the practice of BSE among black women in the US found that $89.0 \%$ of respondents indicated practicing BSE during the past year, $74.0 \%$ indicated having done so during the past six months, and 39.0\% indicated performing self exam monthly. Similar percentage of US women reporting practice of BSR monthly or more often have been reported by other investigators. [11]

\section{Conclusion}

The results of this study revealed a poor knowledge and inadequate early detection and preventive practices among women with family history of breast cancer in spite of their susceptibility to the disease. Health education programme is urgently needed to rectify the poor knowledge and inadequate practices.

\section{References}

[1] Cherry, C., \& Weiss, M. C. (2006). Who gets breast cancer? Retrieved November 7, 2006, from http://www.breastcancer.org/cmm_who_1dx.html (s)

[2] Adebamowo CA, Ajayi OO. Breast cancer in Nigeria. West Afr J Med. 2000;19:179-91. [PubMed]

[3] Banjo AAF. Overview of breast and cervical cancers in Nigeria: are there regional variations? Paper presentation at the International workshop on new trends in Management of breast and cervical cancers, Lagos, Nigeria. 2004.

[4] Mandong, B. M., Madaki, A. K. J., \& Manasseh, A. N. . Malignant Disease in Jos: A follow up. Annals of African Medicine 2004; 2(2): 49-53. (

[5] Okobia, M. N., Bunker, H. C., Okonofua, F. E., \& Osime, U. F. . Knowledge, attitudes and practices of Nigeria women toward breast cancer. World Journal of Oncology 2006; 4:11 Retrieved April 25, 2010, from http://ukpmc.ac.uk/articlerender.cgi?tool=pubmed\&pubmedid=16504034. (ㅇ)

[6] Odusanya, O. O. Breast cancer: Knowledge, attitudes and practices of female school teachers in Lagos, Nigeria. Breast Journal 2001; 7(3): 171-175. [PubMed]

[7] Odusanya OO, Tayo OO. Breast cancer knowledge, attitudes and practice among nurses in Lagos, Nigeria. Acta Oncol. 2001;40:844-848. doi: 10.1080/02841860152703472. [PubMed] [Cross Ref]

[8] Uche EE. Cancer awareness among a Nigerian population. Trop Doct. 1999;29:39-40. [PubMed]

[9] Ajayi IO, Adebamowo CA. Knowledge, belief and attitudes towards breast cancer in southwestern Nigeria. Cancer strategy. $1999 ; 1: 20-24$.

[10] Jacob TC, Penn NE, Brown M. Breast self-examination: knowledge, attitudes, and performance among black women. J Natl Med Assoc. 1989;81:769-776. [PMC free article] [PubMed]

[11] Celentano DD, Holtzman D. Breast self-examination competency: an analysis of self-reported practice and associated characteristics. Am J Public Health. 1983;73:1321-1323. [PMC free article] [PubMed]

[12] Grunfeld EA, Ramirez AJ, Hunter MS, Richards MA. Women's knowledge and beliefs regarding breast cancer. Br J Cancer. 2002;86:1373-1378. doi: 10.1038/sj.bjc.6600260. [PMC free article] [PubMed] [Cross Ref]

[13] Gotzsche PC, Nielsen M: Screening for breast cancer with mammography. Cochrane Database Syst Rev 2006., (4): Art No.: $\mathrm{Cd} 001877$

[14] Miller AB, To T, Baines CJ, Wall C: The Canadian National Breast Screening Study-1: breast cancer mortality after 11 to 16 years of follow-up. A randomized screening trial of mammography in women age 40 to 49 years. Ann Intern Med 2002,137 (5 Part 1$)$ : 305-312 [PubMed]

[15] Michael N Okobia, Clarean H Bunker, Friday E Okonofua, Usifo Osime 'Knowledge, attitude and practice of Nigerian women towards breast cancer: A cross sectional study. World J Surg Oncol. 2006; 4:11

[16] Abimbola Oluwatosin, Oladimeji Oladepo. Knowledge of breast cancer and its early detection measures among rural women in Akinyele Local Government Area, Ibadan, Nigeria. BMC Cancer, 2006; 6 ; 271

[17] Ali Montazeri, Mariam Vahdaninia, Iraj Harirchi, Amir M. Harirchi, Akram Sajadian, Fatemeh Khaleghi, Mandana Ebrahim, Shahpar Haghighat, Soghra Jarvandi. Breast cancer in Iran: need for greater women awareness of warning signs and effective screening methods. Asia Pacific Family Medicine 2008,7:6 